Article

\title{
Techniques for Thin-Walled Element Milling with Respect to Minimising Post-Machining Deformations
}

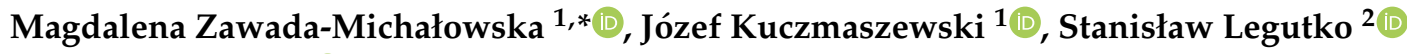 \\ and Paweł Pieśko ${ }^{1}$ (D) \\ 1 Faculty of Mechanical Engineering, Lublin University of Technology, 20-618 Lublin, Poland; \\ j.kuczmaszewski@pollub.pl (J.K.); p.piesko@pollub.pl (P.P.) \\ 2 Faculty of Mechanical Engineering, Poznan University of Technology, 60-965 Poznań, Poland; \\ stanislaw.legutko@put.poznan.pl \\ * Correspondence: m.michalowska@pollub.pl; Tel.: +48-81-5384227
}

Received: 15 September 2020; Accepted: 19 October 2020; Published: 22 October 2020

\begin{abstract}
The paper examines the impact of selected machining techniques and the semi-finished product technological history on deformations of thin-walled elements made of EN AW-2024 T351 aluminium alloy after milling. The following techniques have been implemented: High Performance Cutting, High Speed Cutting, conventional finishing (CF) and combinations of these techniques. As for the semi-finished product technological history, the rolling direction has been analysed. It has been assumed that it can be relevant in relation to the cutting tool feed direction and, in consequence, exert considerable impact on the stress, as well as deformation following machining. The interest in this issue proceeds from significant challenges faced by the industry, particularly in the aerospace sector. The analysis of results obtained has shown that milling in the direction perpendicular to the rolling direction results in larger deformations than milling in the parallel direction. Additionally, it has been revealed that applying a correctly selected machining technique makes it possible to minimise post-machining deformations of thin-walled elements.
\end{abstract}

Keywords: deformations; milling; thin-walled elements; aluminium alloys; machining

\section{Introduction}

The growing interest in issues related to thin-walled element machining results from their broad-range applications in various industry sectors, in particular, in the aerospace and automotive industries. In aircraft, thin walls are included in the design of fuselage, control surface, on-board equipment and body, etc. [1-3].

Increasingly frequently, the term "integral (structural) thin-walled elements" is used. Their characteristics comprise a uniform design, relatively high rigidity and low weight in comparison to their overall dimensions and a high strength to empty weight ratio [1,4,5].

Currently, integral elements are manufactured mostly using state-of-the-art 5-axis machining centres by means of high-performance machining techniques, such as: HSC (High Speed Cutting) [6] and HPC (High Performance Cutting). They are very often produced using monolithic plates made of light metal alloys (aluminium, titanium) [7]. In high-performance milling of such elements, chips amount to as much as $95 \%$ of the semi-finished product weight $[4,5,8-13]$.

One of the main problems encountered during thin-walled element machining are elastic and plastic deformations. Elastic deformations result in geometry errors, vibrations and machined surface quality deteriorations. They are caused by the phenomenon of the workpiece sagging under the cutting edge impact. Plastic deformations result in shape errors and generate residual stresses which are difficult to eliminate from the element's surface layer and cause permanent alterations of its size and 
shape. In industrial practice, among others, interoperational heat treatment, e.g., relief annealing is used to remove residual stresses. Due to economic reasons, such operations are being eliminated, as they generate additional costs and increase the production time significantly [4,9,14-18].

In the industry, problems related to large-sized thin-walled elements and their significant deformations occurring directly after removing the clamping forces are quite common. It is assumed that the reasons for the occurring deformations can be as follows [19-21]:

- $\quad$ post-machining residual stresses introduced during machining;

- $\quad$ residual stresses introduced during semi-finished product manufacturing (i.e., technological history effect);

- $\quad$ residual stresses introduced during heat treatment.

Thus, the end condition of residual stresses in the surface layer, after machining, is important [19,21].

During machining, plastic deformation of the workpiece material occurs around the cutting tool tip, which, after removing the factor that has caused it, creates compressive residual stresses in the surface layer. Additionally, machining processes generate heat (among others, as a result of friction) that results in considerable temperature differences in the cutting zone, and thermal stresses exceeding the material yield point, which, in consequence, causes tensile residual stresses in the surface layer. It should also be taken into account the fact that structural changes and resulting volume changes occur in a material [22-24].

It is assumed that, after machining, mainly mechanical stresses (pressure) and thermal stresses (temperature), operating in the opposite direction, dominate in the surface layer. In reality, both factors impact the residual stress condition; however, their intensity may vary. The mechanical model mostly refers to machining, and the thermal model is characteristic for abrasive machining and HSC. It must be highlighted that residual stresses occur at the depth of a few decimals of a millimetre and depend on numerous factors, e.g., machining parameters, tool geometry and machining methods [25-31].

Thin-walled aircraft components are often designed as pocket-like elements mostly made of wrought aluminium alloys. In such cases, rolled plates are usually used as semi-finished products, having different structural and mechanical properties in particular directions, in relation to the rolling direction (anisotropy phenomenon). It is related to the accumulation of residual stresses resulting from the semi-finished product technological history. During machining, the balance of the underlying stress condition is disrupted and new stresses are introduced, which results in the occurrence of undesirable deformations [19,21,32-36].

Thin-walled element deformations are difficult to forecast, as, apart from residual stresses, they result from a number of other factors, including: temperature, clamping force, cutting force, tool geometry, etc. [13,19,30,37-41].

Additionally, common problems related to thin-walled element machining include [15,42-44]:

- maintaining good surface quality;

- difficulties in ensuring required dimensional and shape accuracy;

- the presence of self-excited vibrations ("chatter") disturbing the machining process stability.

More and more often, cutting fluids are being eliminated from the machining process, mainly due to their negative impact on the environment. Methods such as Minimum Quantity Cooling Lubrication (MQCL) and Minimum Quantity Lubrication (MQL) become alternatives to traditional cooling methods that are now widely used, e.g., during manufacturing of the thin-walled elements $[45,46]$.

The enhancement of dimensional and shape accuracy of manufactured thin-walled elements is obtained by the application of the following machining error minimisation methods $[10,16,17,47,48]$ :

- $\quad$ correct milling strategy selection;

- $\quad$ increase in cutting speed $v_{c}$ (HSC);

- $\quad$ rationalisation of cutting parameters (in particular: feed per tooth $f_{z}$ and milling width $a_{e}$ ) aimed at decreasing the component of cutting force perpendicular to a wall being machined. 
It must be stressed that the correlation between the selection of correct procedures aimed at minimising post-machining errors and types of machined materials is also significant.

The choice of an optimum thin-walled element machining strategy mostly depends on the ratio between the machined wall height and its thickness. Due to the above, three cases can be identified $[17,48,49]$ :

- low height to thickness ratio < 15:1—where separate milling of each wall side in non-overlapping passes is recommended;

- $\quad$ moderate height to thickness ratio <30:1:

- milling on a constant level—alternate machining at a constant depth of cut $a_{p}$ of both side walls, also in non-overlapping passes;

- milling at a difference of levels-alternate milling of both side walls with non-overlapping levels between consecutive passes; the depth of cut $a_{p}$ at the first pass should be $a_{p} / 2$;

- high height to thickness ratio $>30: 1$-Where it is recommended to change the sides and apply the "christmas tree" routine in order to achieve the wall thickness setpoint in stages.

Generally, as a rule, thin wall machining processes are planned in such a manner that non-machined material locally supports the material being machined [50]. The number of tool passes mostly depends on the milled wall dimensions and assumed depth of cut $a_{p}$. It is also recommended that the duration of cutting edge contact with a workpiece should be decreased in thin-walled element machining. It can be achieved by applying increased cutting speed $v_{c}$, a low $a_{p} / a_{e}$ coefficient and feed in range of $0.02-0.05$ $\mathrm{mm} /$ tooth. Additionally, it is advisable to provide an $0.1-1 \mathrm{~mm}$ allowance for finishing $[16,17,46]$.

Authors $[36,51]$ specify the following thin-walled element deformation minimisation methods:

- cutting parameter optimisation;

- tool geometry optimisation;

- tool path optimisation;

- designing a special clamping device;

- simultaneous workpiece wall machining on either side.

In machining, particularly in relation to aircraft components, the "8:1 rule" also applies, i.e., it is recommended that $1 \mathrm{~mm}$ thick walls should be milled using the depth of cut $a_{p}$ equal to $8 \mathrm{~mm}$ or less. Other applicable guidelines specify that it is advisable to leave the stiffening ribs (mostly on the side opposite to the machined surface) which must be removed at the end of the process. The guidelines presented are based on available industrial experience gained using the trial and error method [51,52].

The simulations performed in the paper [37] have shown that, in order to improve the dimensional and shape accuracy and machined thin-walled element surface quality, variable cutting parameters for each layer must be applied.

Recommendations regarding thin-walled element manufacturing on their entire height have also become quite common. In such cases, tools with high rigidity and correct geometry must be used [44].

During thin-walled plate machining, the tool penetration process should be started from the middle, using the helical interpolation. Next, the machining should be continued outwards from the assumed starting point. While milling a surface with the opposite side already machined, minimum pressure should be applied, and tools with a minimum number of cutting edges should be used [46].

Summing up the literature analysis conducted, one may conclude that the majority of papers include theoretical scientific considerations and numerical simulations forecasting the size of occurring deformations. They fail to present application-related information and technological guidelines that might facilitate solving significant problems encountered by the machine industry, related to the presence of thin-walled element deformations following machining processes. Only a few papers attempt to perform experiment-based verification of the theoretical models created, and identify the possibilities of practical applications in techniques employed to manufacturing such elements. 
The aims of the paper are to indicate the milling technique that ensures the smallest post-machining deformations of thin-walled elements made of EN AW-2024 T351 aluminium alloy and to determine the influence of the technological history of the semi-finished product on the value and type of deformations as well as to define the recommended minimum thickness of the surface layer after the rolling that has to be removed during pre-machining.

\section{Materials and Methods}

The research object model, including independent and dependent variables as well as constant and disturbing factors, is presented in Figure 1.

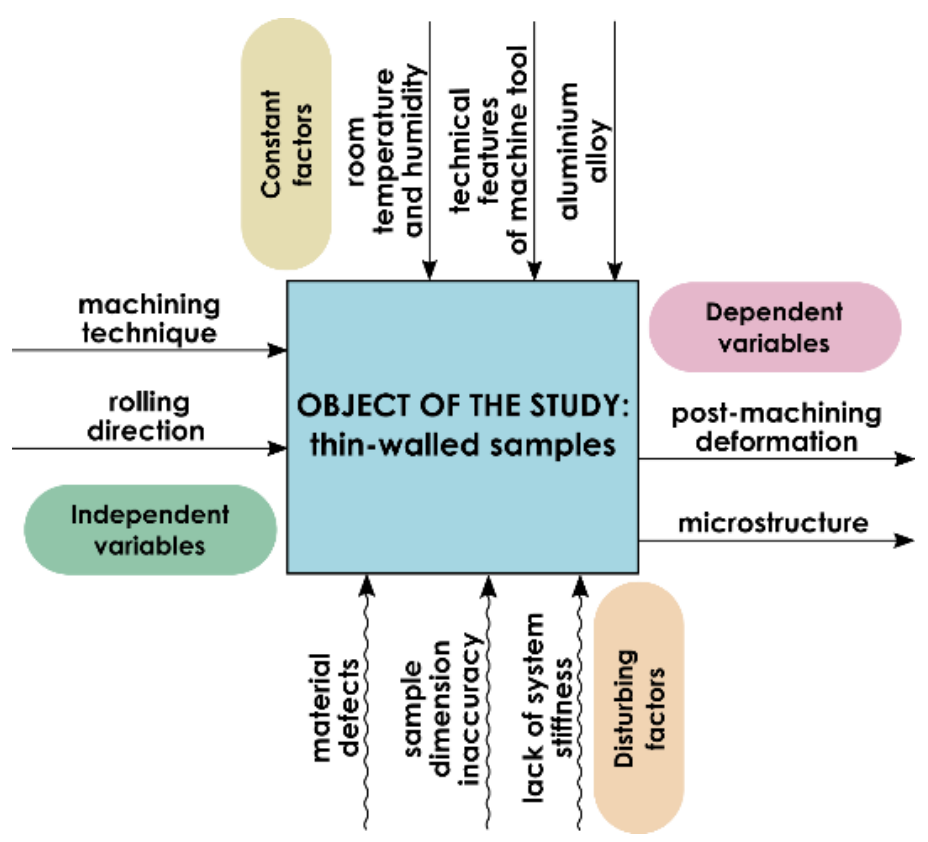

Figure 1. Research object model.

The research object comprised thin-walled samples made of EN AW-2024 T351 aluminium alloy of the following dimensions: $45 \mathrm{~mm} \times 210 \mathrm{~mm} \times 10 \mathrm{~mm}$ (Figure 2). The machining technique and rolling direction were assumed as the independent variables. The analysed dependent variables included post-machining deformation and the surface layer microstructure. The constant factors were machine tool technical features, laboratory temperature and humidity as well as the material type. The disturbances included material defects, sample dimension inaccuracy and lack of system (machine tool-clamping device-workpiece-cutting tool) rigidity.

The research was performed in relation to five machining techniques, i.e.,

- High Performance Cutting;

- High Performance Cutting and conventional finishing (CF);

- High Performance Cutting and High Speed Machining;

- High Speed Cutting;

- High Speed Cutting and conventional finishing (CF).

The relation between the cutting tool feed direction and the rolling direction, defined as the technological history effect, was another independent variable subject to examination. Two variability levels were assumed: 
- cutting tool feed direction perpendicular to rolling direction (perpendicular direction);

- cutting tool feed direction parallel to rolling direction (parallel direction).

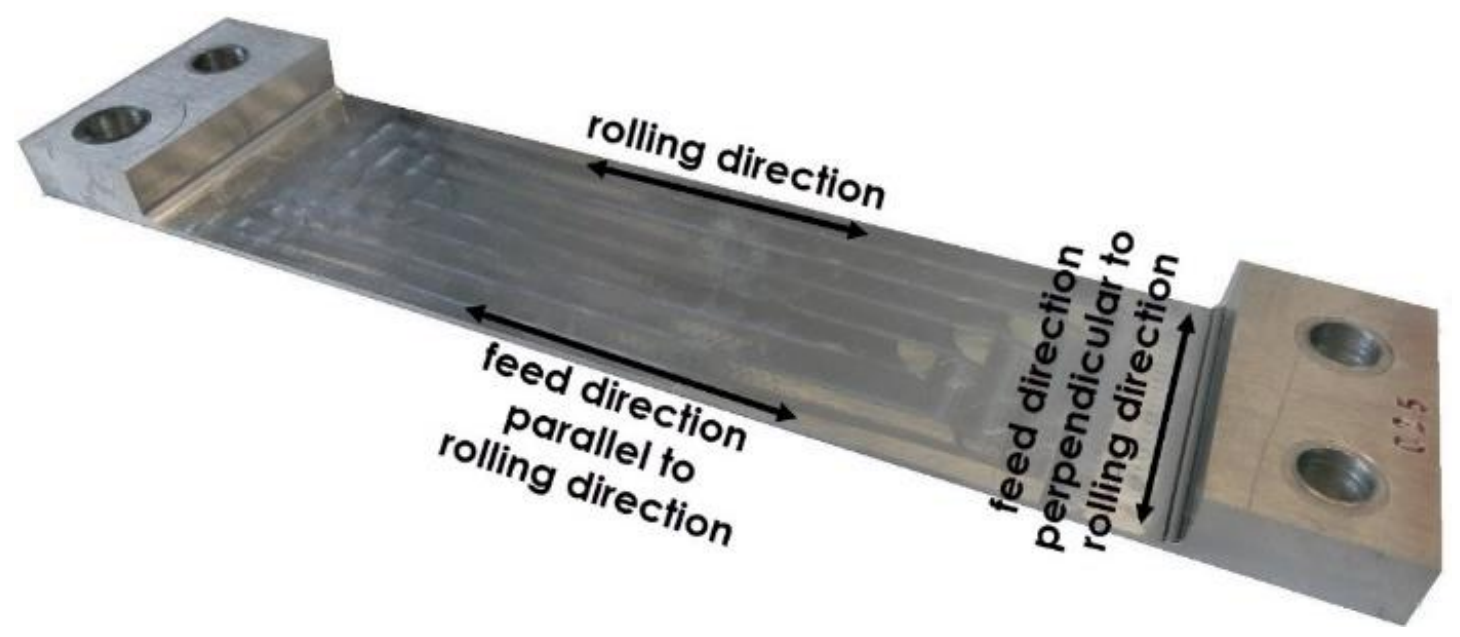

Figure 2. View of a sample after milling, with the relation between the cutting tool feed direction and milling direction indicated.

Figure 2 shows a view of a thin-walled sample after milling, with the relation between the cutting tool feed direction and milling direction indicated. The created pocket dimensions were $45 \mathrm{~mm} \times 160 \mathrm{~mm}$, and the bottom thickness was $1 \mathrm{~mm}$. The sample, in addition to the part subject to analysis, also has left ends for the samples clamping during machining. The holes were used to jig samples in the clamping device (ensuring uniform clamping conditions). The adoption of such geometric solution ensures repeatability of the clamping in the entire series of samples and eliminates the influence of the clamping forces on the deformation process. In the study, the research was carried out on flat samples, it was the most favourable solution to achieve the goals.

The paper deliberately assumed that the surface on the side opposite to the machined surface would remain unmachined, which is not typical in the processes of manufacturing elements from this type of semi-finished products. The goals of the solution are:

- the assessment of the impact of the rolling technological history on the deformation of thin-walled elements after machining;

- defining the minimum allowance of the rolled surface layer to be removed in elements manufactured from such semi-finished products.

The research was based on samples cut out of a rolled plate made of the EN AW-2024 wrought aluminium alloy, in the T351 condition. It is one of the most popular multi-component aluminium alloys which, due to its high strength, is widely used in the aerospace industry to manufacture, e.g., wing sheathing and airframe fuselage. The EN AW-2024 alloy is characterised with good machining properties and is supplied following various thermal treatment variants which exert considerable impact on its mechanical properties. However, its disadvantages include low corrosion resistance and limited weldability. The chemical composition of EN AW-2024 aluminium alloy is presented in Table 1.

Table 1. The chemical composition of EN AW-2024 aluminium alloy: own prepared based on [53].

\begin{tabular}{ccccccccccc}
\hline \multicolumn{10}{c}{ Chemical Composition, \% } \\
\hline $\mathrm{Si}$ & $\mathrm{Fe}$ & $\mathrm{Mg}$ & $\mathrm{Cu}$ & $\mathrm{Mn}$ & $\mathrm{Zn}$ & $\mathrm{Cr}$ & $\mathrm{Zr}+\mathrm{Ti}$ & $\mathrm{Ti}$ & Other & $\mathrm{Al}$ \\
$\leq 0.5$ & $\leq 0.5$ & $1.2-1.8$ & $3.8-4.9$ & $0.3-0.9$ & $\leq 0.25$ & $\leq 0.1$ & $\leq 0.2$ & $\leq 0.15$ & $\leq 0.15$ & Rest \\
\hline
\end{tabular}


The EN AW-2024 T351 aluminium alloy has the following properties [54]:

- density, $\rho=2.78 \mathrm{~g} / \mathrm{cm}^{3}$;

- Young's modulus, $E=73 \mathrm{GPa}$;

- $\quad$ tensile strength, $R_{m}=469 \mathrm{MPa}$;

- $\quad$ offset yield strength, $R_{p 0.2}=324 \mathrm{MPa}$;

- Brinell hardness, $120 \mathrm{HB}$.

Machining was performed with the Avia VMC 800 HS vertical machining center (FABRYKA OBRABIAREK PRECYZYJNYCH AVIA S.A., Warsaw, Poland) with the Heidenhain iTNC 530 control (Heidenhain, Traunreut, Germany).

Three milling cutters were used in the studies, i.e.,

- indexable milling cutter by Kennametal (25A03R044B25SED14) (Kennametal, Pittsburgh, PA, USA) with correctly selected cutting inserts (EDCT140416PDFRLDJ)—used for HPC (Figure 3a);

- $\quad$ monolithic carbide milling cutter by Sandvik (R216.33-16040-AC32U) (Sandvik, Stockholm, Sweden) without a protective coat-used for HSC and conventional finishing (CF) (Figure 3b).

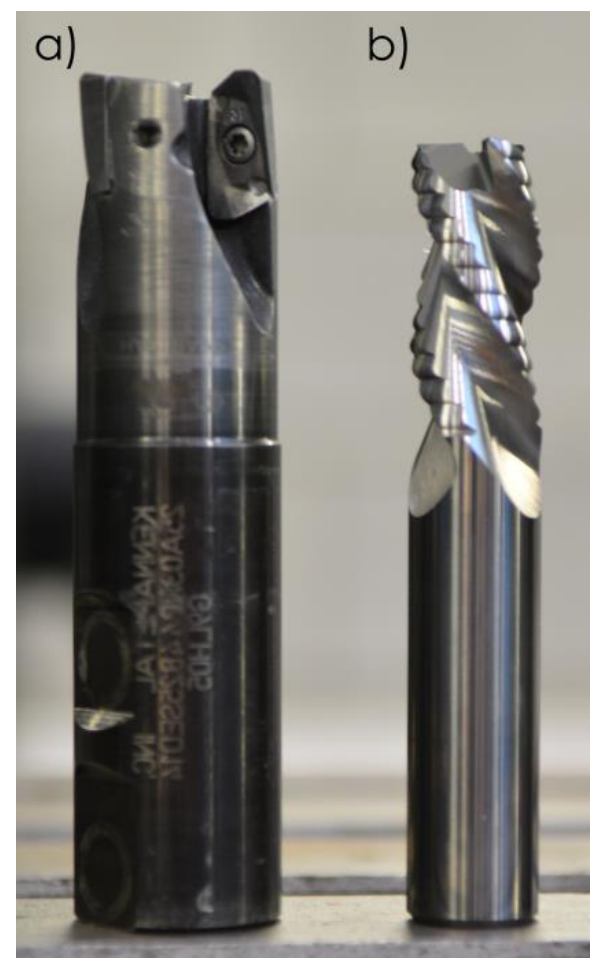

Figure 3. Tools used in studies: (a) Kennametal indexable milling cutter; (b) Sandvik monolithic milling cutter.

Due to the fact that the Sandvik milling cutter is dedicated to roughing, the explanation is needed. The geometry of the Sandvik tool used in the form of the Kordell geometry, apart from the chip breaker, does not differ from the milling cutter for finishing. In this case, HSC and conventional machining with small depths of cut were used, so the cutter working part with chip breaker was not used.

Tool selection was based on the current range of milling cutters employed in the aluminium alloy machining (ISO N group), particularly taking into account possibility of their use for High Performance Cutting and High Speed Cutting. Specifications of tested milling cutters are shown in Table 2. 
Table 2. Specifications of milling cutters used [55,56].

\begin{tabular}{ccc}
\hline Symbol & $\begin{array}{c}\text { Kennametal } \\
\text { 25A03R044B25SED14 }\end{array}$ & $\begin{array}{c}\text { Sandvik } \\
\text { R216.33-16040-AC32U }\end{array}$ \\
\hline Material & KC410M & H10F \\
Number of teeth, $z$ & 3 & 3 \\
Working part diameter $d, \mathrm{~mm}$ & 25 & 16 \\
Overall length $L, \mathrm{~mm}$ & 101 & 92 \\
Maximum depth of cut $a_{p m a x}, \mathrm{~mm}$ & 14.6 & 32 \\
Clamping part diameter $d, \mathrm{~mm}$ & 25 & 16 \\
\hline
\end{tabular}

According to the tool materials, $\mathrm{KC} 410 \mathrm{M}$ and $\mathrm{H} 10 \mathrm{~F}$ are a trade mark used by the manufacturers. Kennametal reports that it is a carbide coated with TiB2 protective coating applied by the PVD method and Sandvik gives information that it is a tungsten carbide without any protective coating.

The cutting parameter values used for each machining technique analysed are presented in Table 3.

Table 3. Cutting parameter values for specific machining techniques.

\begin{tabular}{|c|c|c|c|c|c|c|c|c|}
\hline \multirow{3}{*}{$\begin{array}{c}\text { Cutting } \\
\text { Parameters }\end{array}$} & \multicolumn{8}{|c|}{ Techniques } \\
\hline & \multirow{2}{*}{ HPC } & \multicolumn{2}{|c|}{$\mathrm{HPC}+\mathrm{CF}$} & \multicolumn{2}{|c|}{ HPC + HSC } & \multirow{2}{*}{ HSC } & \multicolumn{2}{|c|}{$\mathrm{HSC}+\mathrm{CF}$} \\
\hline & & HPC & $\mathrm{CF}$ & HPC & HSC & & HSC & CF \\
\hline Depth of cut $a_{p}, \mathrm{~mm}$ & 4.5 & 4.3 & 0.4 & 4.3 & 0.4 & $0.956 ; 0.4^{*}$ & 0.956 & 0.4 \\
\hline Milling width $a_{e}, \mathrm{~mm}$ & 18.75 & 18.75 & 12 & 18.75 & 12 & 12 & 12 & 12 \\
\hline Cutting speed $v_{\mathcal{C}}, \mathrm{m} / \mathrm{min}$ & 1000 & 1000 & 200 & 1000 & 1200 & 1200 & 1200 & 200 \\
\hline $\begin{array}{l}\text { Feed per tooth } f_{z} \\
\mathrm{~mm} / \text { tooth }\end{array}$ & 0.1 & 0.1 & 0.02 & 0.1 & 0.02 & 0.02 & 0.02 & 0.02 \\
\hline Rotational speed $n, \mathrm{rpm}$ & 12,732 & 12,732 & 3979 & 12,732 & 23,873 & 23,873 & 23,873 & 3979 \\
\hline Number of passes $i$ & 2 & 2 & 1 & 2 & 1 & $9 ; 1^{*}$ & 9 & 1 \\
\hline
\end{tabular}

The cutting parameters were selected both on the basis of tool manufacturers' recommendations and authors' own experience. Additionally, the flood cooling with an aqueous solution of cooling oil based on MobileCut 230 coolant concentrate (Mobil industrial, Spring, TX, USA) was used.

The deformations were studied by means of the strain gauge method using Tenmex TF-5-2x foil strain gauges (Tenmex, Łodź, Poland). Two individual strain gauges were glued to examined sample surface in its central part, according to following directions (Figure 4):

- $\quad x$-parallel to the longer sample edge (longitudinal strain gauge);

- $\quad y$-perpendicular to the longer sample edge (transversal strain gauge).

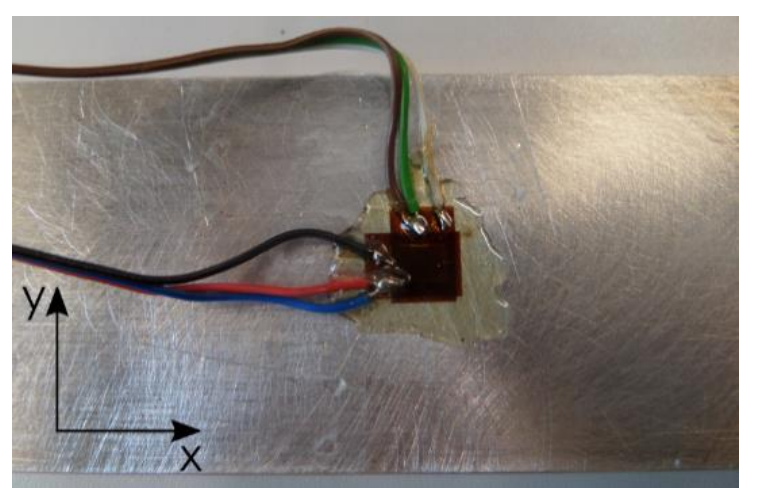

Figure 4. Foil strain gauges glued on sample surfaces. 
The selection of the place was related to the prediction of the greatest strains in this part, while one strain gauge in each direction was enough to measure these strains.

The process of attaching strain gauges to the examined sample surfaces was conducted in line with a standard procedure. The LOCTITE 401 cyanoacrylate adhesive (Henkel, Düsseldorf, Germany) was used plus the M-COAT A AIR DRYING POLYURETHANE COATING (Micro-Measurements, Wendell, NC, USA) to protect strain gauges against impact exerted by a coolant and other external factors. The measurement system used in the examination included strain gauges which, by means of soldered conductors, were connected with SCMSG120 adapters, HBM 1-MX840A universal measurement amplifier (HBM, Darmstadt, Germany), optoelectronic connector and computer with the CatmanEasy V35.1 DAQ PROJECT software installed to process, analyse and visualise the measurement results obtained. The examination was repeated five times for each configuration analysed.

The study consisted of examining the surface layer microstructures, both before and after milling, taking into account all configurations analysed. The Nikon Epiphot inverted metallographic microscope (Nikon, Tokio, Japan) with the ToupView software installed was used to examine the structures. The locations where samples used to prepare metallographic specimens were taken, including highlighting of the examined surfaces, are presented in Figure 5a (sample prior to machining) and Figure $5 \mathrm{~b}$ (sample after machining).

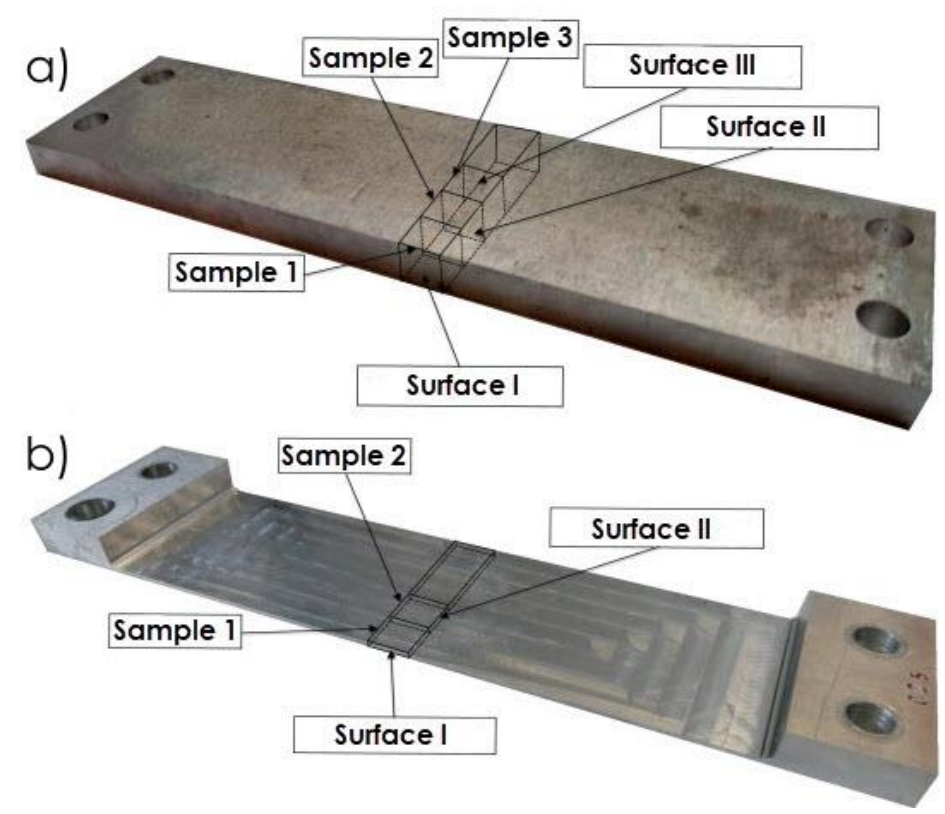

Figure 5. Locations where samples used to prepare metallographic specimens were taken, including highlighting of the examined surfaces: (a) sample prior to machining; (b) sample after machining.

The aim of the microstructures was to compare the depth of textured surface layer after the rolling and the milling for various techniques analysed in the study as well as to define the recommended minimum thickness of the surface layer after the rolling that has to be removed during pre-machining.

Metallographic specimens were prepared following the standard procedure applied for aluminium alloys. Firstly, the samples were ground with sandpaper of increasing grit number, polished with the MetaDi diamond suspension (Buehler, Lake Bluff, IL, USA) and OP-S NonDry aluminium oxide suspension (Struers, Cleveland, OH, USA). After polishing, surfaces were etched using Mi2Al solution.

\section{Results}

The examination concentrated on relative deformation $\varepsilon$ sign and values during the stabilisation phase, after removing a sample from a clamping device and stabilising it to the ambient temperature level. Figure 6 presents relative deformations cobtained for the machining techniques examined, 
in which the milling direction was respectively perpendicular and parallel to the rolling direction. Relative deformations $\varepsilon$ were expressed in $\mu \mathrm{m} / \mathrm{m}$, showing by how many $\mu \mathrm{m}$ units an element was deformed along a $1 \mathrm{~m}$ long section. The obtained results showed that, regardless of the relation between the milling direction and rolling direction, larger relative deformations $\varepsilon$ were detected on longitudinal strain gauges. "-" means that strain gauges were stretched. Due to the noticeable relationship between the relative deformation $\varepsilon$ values obtained on strain gauges glued perpendicularly and in parallel to the longer sample edge, it was decided to consider the results of relative strain $\varepsilon$ from the longitudinal strain gauge, in the further part of this paper. For milling perpendicular to the rolling direction, maximum relative deformations $\varepsilon$ were obtained using the HPC technique, i.e., $\varepsilon=-402.59 \mu \mathrm{m} / \mathrm{m}$, and minimum deformations were obtained using the HSC technique combined with conventional finishing (CF), i.e., $\varepsilon=$ $-168.66 \mu \mathrm{m} / \mathrm{m}$ (almost $60 \%$ less in relation to HPC). In the case of milling parallel to the rolling direction, an analogous relationship was observed. The largest relative deformations $\varepsilon$ were present following HPC, i.e., $\varepsilon=-301.28 \mu \mathrm{m} / \mathrm{m}$, and the smallest ones following HSC combined with conventional finishing (CF), i.e., $\varepsilon=-51.59 \mu \mathrm{m} / \mathrm{m}$ (over $80 \%$ less in comparison with HPC).
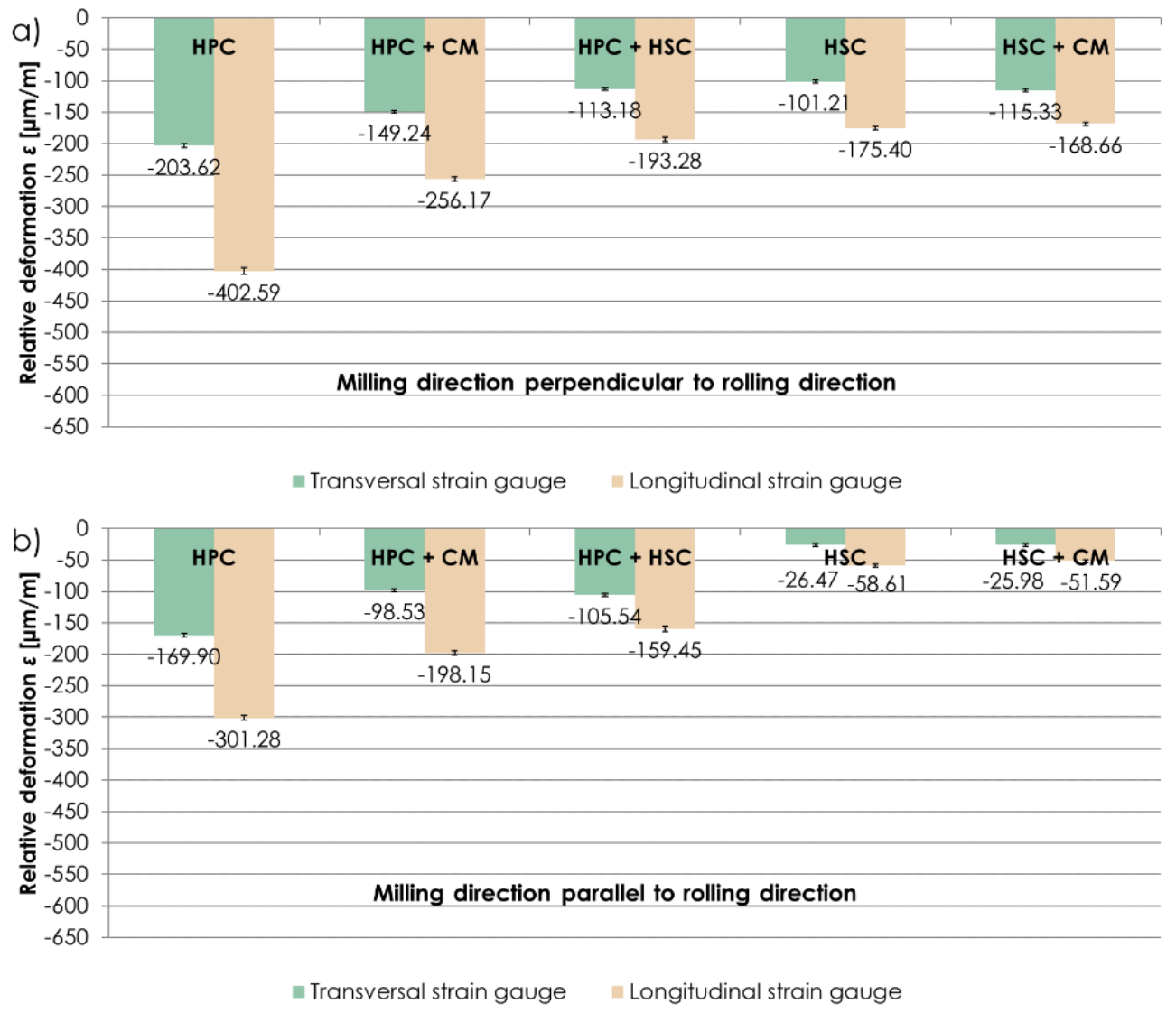

Figure 6. Relative deformations cobtained using the analysed machining techniques, and with (a) perpendicular, (b) parallel relationship between the milling direction to the rolling direction.

Figure 7 shows a comparison of relative deformations $\varepsilon$ obtained on longitudinal strain gauges, depending on the relationship between the milling direction and rolling direction. While analysing the results, it was established that samples milled perpendicularly to the rolling direction were subject to larger relative deformations $\varepsilon$ than samples milled in parallel to the rolling direction. With HPC, combination of HPC with conventional finishing (CF) and combination of HPC with HSC, the difference between relative deformations $\varepsilon$ was approximately $30 \%$ (in relation to the parallel direction). In the case of HSC and combination of HSC with conventional finishing (CF), relative deformations $\varepsilon$ were $200 \%$ larger with milling in the direction perpendicular to the rolling direction than in the parallel direction. 


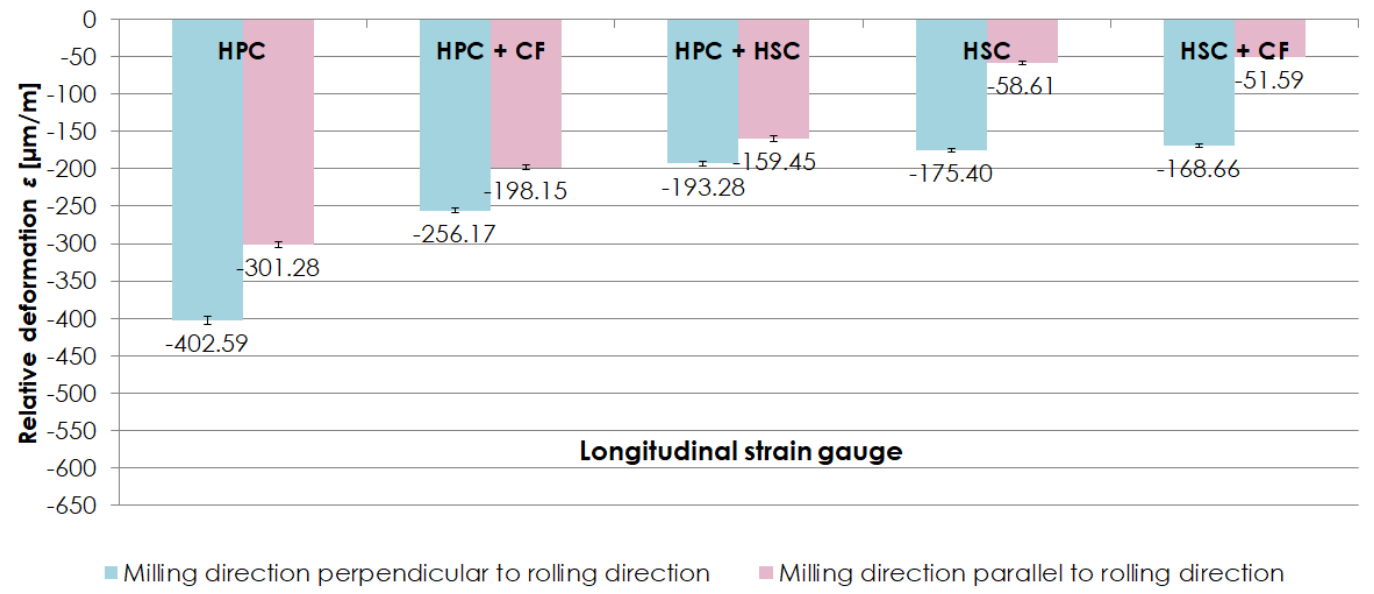

Figure 7. Comparison of relative deformations $\varepsilon$ obtained on longitudinal strain gauges, depending on the relationship between the milling direction and rolling direction.

The analysis of the results obtained in the relative deformation $\varepsilon$ examination performed on thin-walled samples made of EN AW-2024 aluminium alloy in the T351 condition enabled to conclude that, regardless of the milling technique analysed, higher relative deformations $\varepsilon$ were obtained after milling in the direction perpendicular to the rolling direction. A possibility to reduce relative deformations हby applying a correct machining technique was also observed.

During the first stage of the microstructure observations, samples prior to the milling process were taken into account. The first step was to analyse the surfaces designated as I, II and III in Figure 5a. Figure 8 presents views of the microstructure of surface I for samples cut out in the direction perpendicular to the rolling direction, at the following magnification: $2.5 \times$ and $20 \times$, and Figure 9 shows analogous views for the parallel direction. Thus, both the core structure and surface layer resulting from rolling were taken into account.

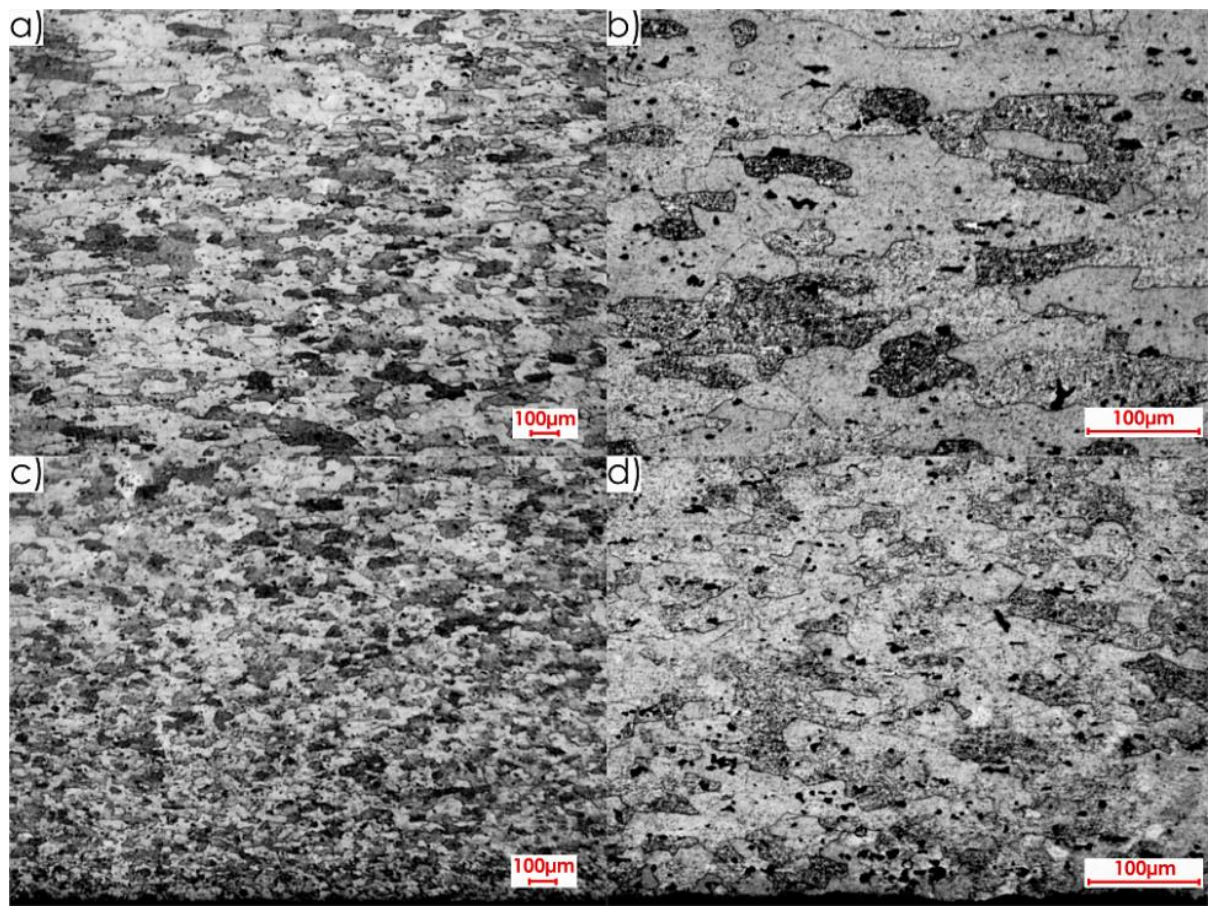

Figure 8. Microstructure of surface I for perpendicular rolling direction: core: (a) 2.5× magnification,

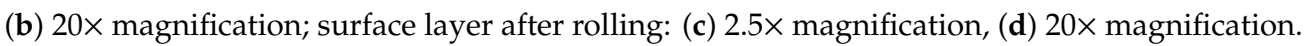




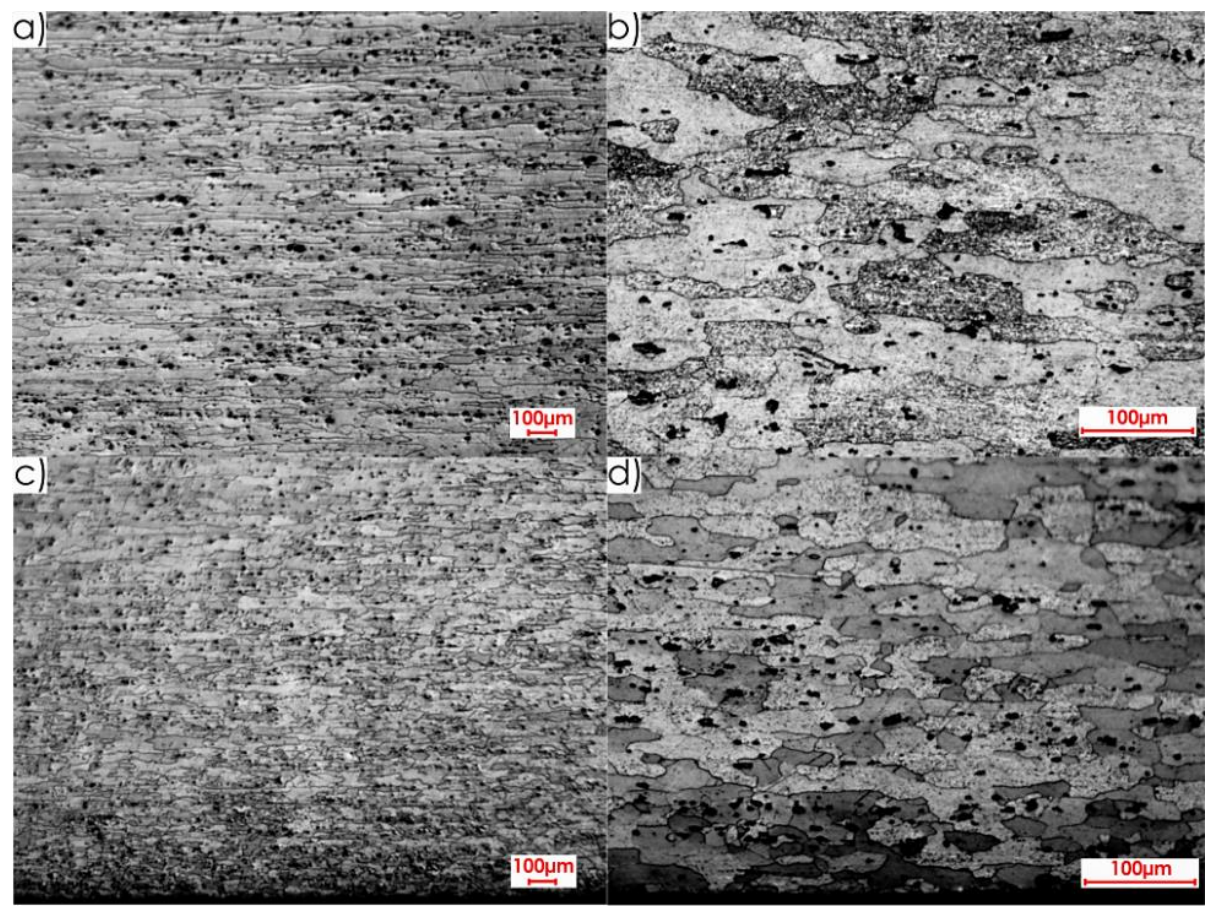

Figure 9. Microstructure of surface I for parallel rolling direction: core: (a) $2.5 \times$ magnification, (b) $20 \times$ magnification; surface layer after rolling: (c) $2.5 \times$ magnification, (d) $20 \times$ magnification.

The microstructures of both core and surface layer after rolling observed on surface II for the perpendicular and parallel rolling direction, at 20× magnification, are shown in Figures 10 and 11.

Figures 12 and 13 show the microstructures of surface III for the perpendicular and parallel rolling direction obtained at the following magnification: $2.5 \times$ and $20 \times$.

Next, images of the microstructure of thin-walled samples ( $1 \mathrm{~mm}$ thick) were analysed after the milling, taking account of the techniques studied and the rolling directions considered. Focus was directed at surfaces designated as I and II in Figure 5b. Due to slight differences in the microstructure for individual machining techniques, results are presented only for one selected technique, i.e., HPC. Figure 14 presents the microstructure of surface I after milling with the HPC technique and the perpendicular rolling direction obtained at the following magnification: $2.5 \times$ and $20 \times$, whereas Figure 15 shows views for the parallel direction. The structures of both the core and surface layer resulting from rolling and HPC were taken into account.

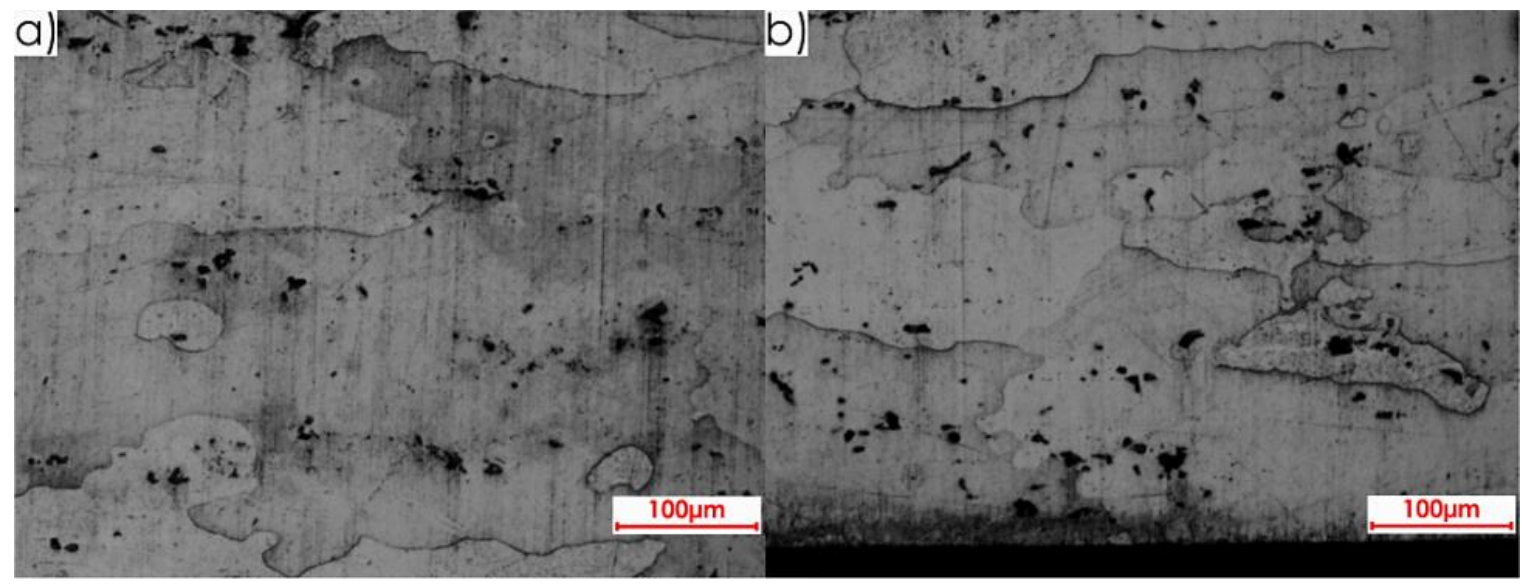

Figure 10. Microstructure of surface II for perpendicular rolling direction (20× magnification): (a) core, (b) surface layer after rolling. 


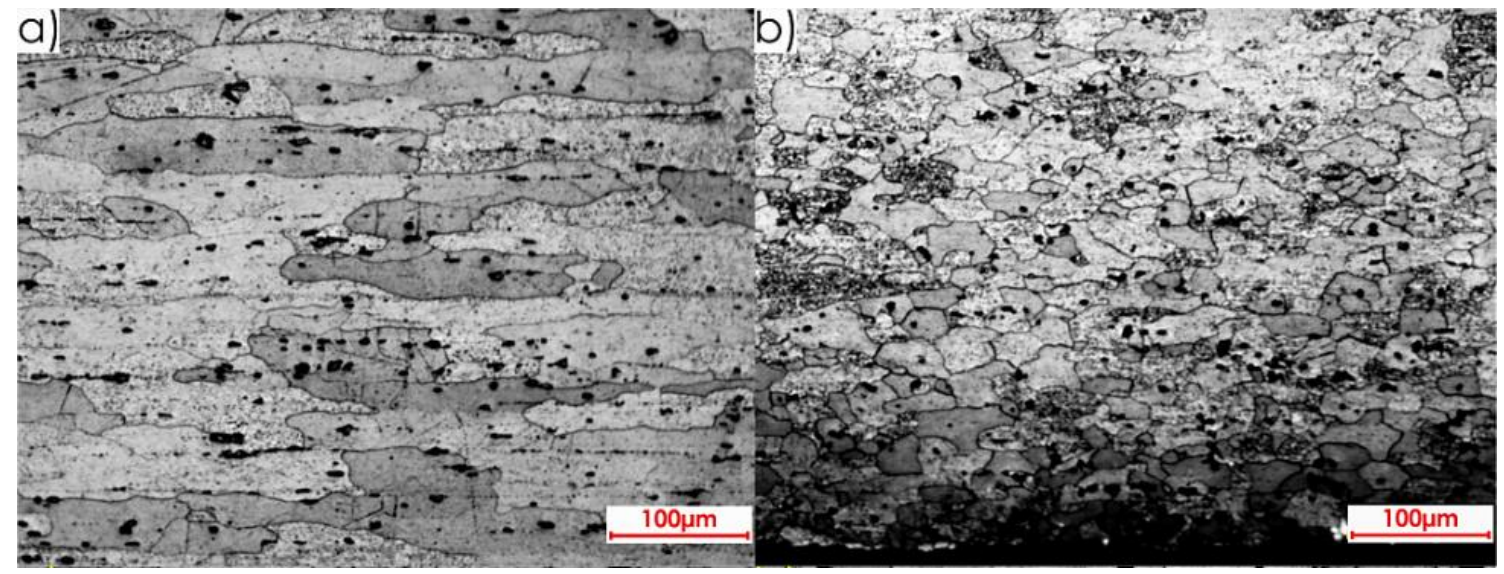

Figure 11. Microstructure of surface II for parallel rolling direction (20× magnification): (a) core,

(b) surface layer after rolling.

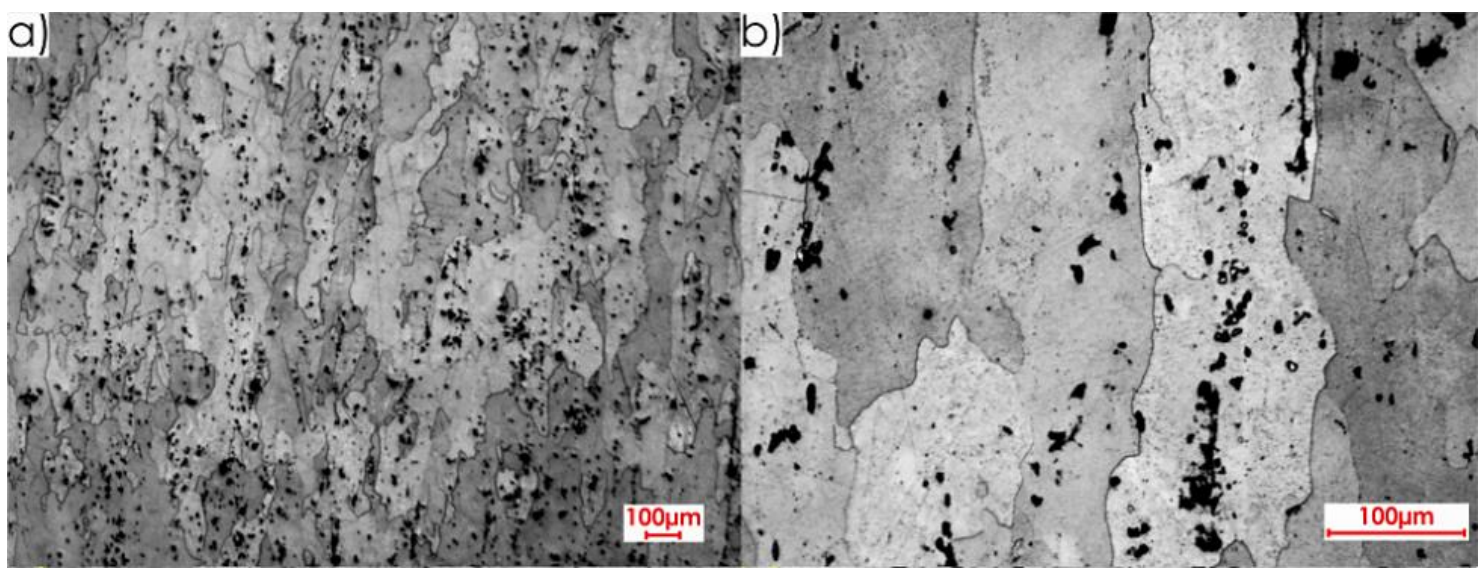

Figure 12. Microstructure of surface III for perpendicular rolling direction: (a) $2.5 \times$ magnification, (b) $20 \times$ magnification.

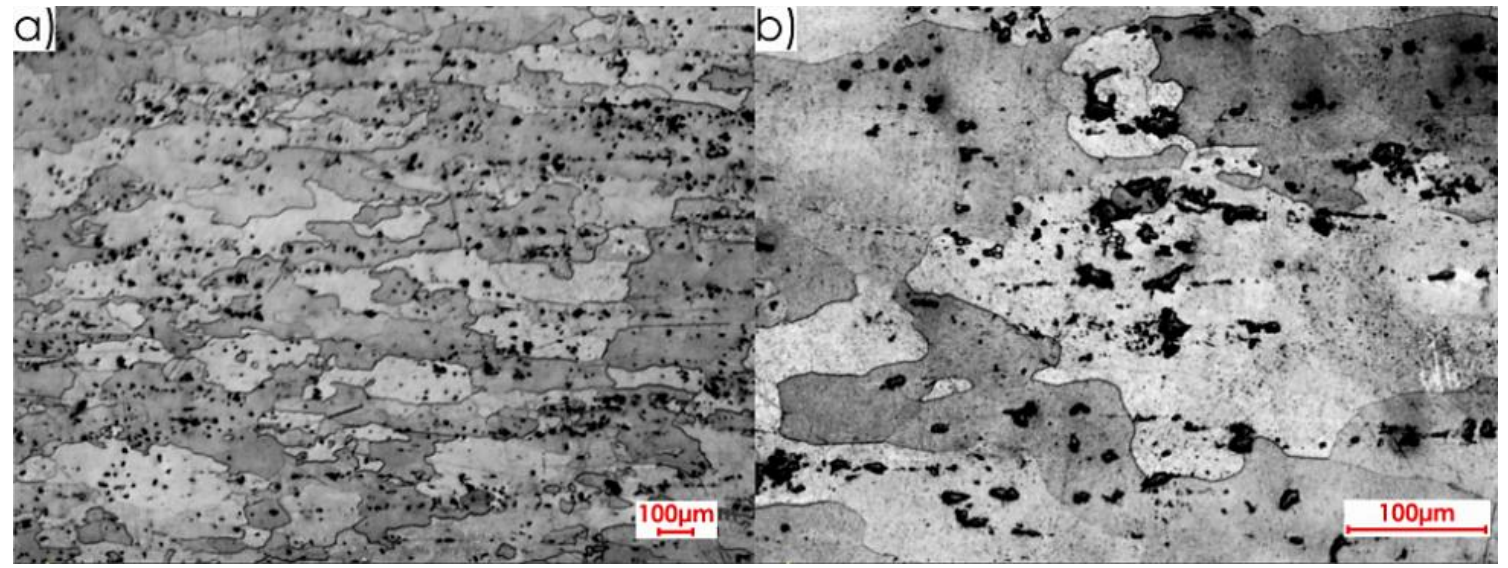

Figure 13. Microstructure of surface III for parallel rolling direction: (a) $2.5 \times$ magnification, (b) $20 \times$ magnification.

Views of the microstructure of both the surface layer and the core, after High Performance Cutting for surface II and the studied rolling directions (perpendicular and parallel), obtained at the applied magnifications (20× and 2.5×, respectively), are shown in Figures 16 and 17. 


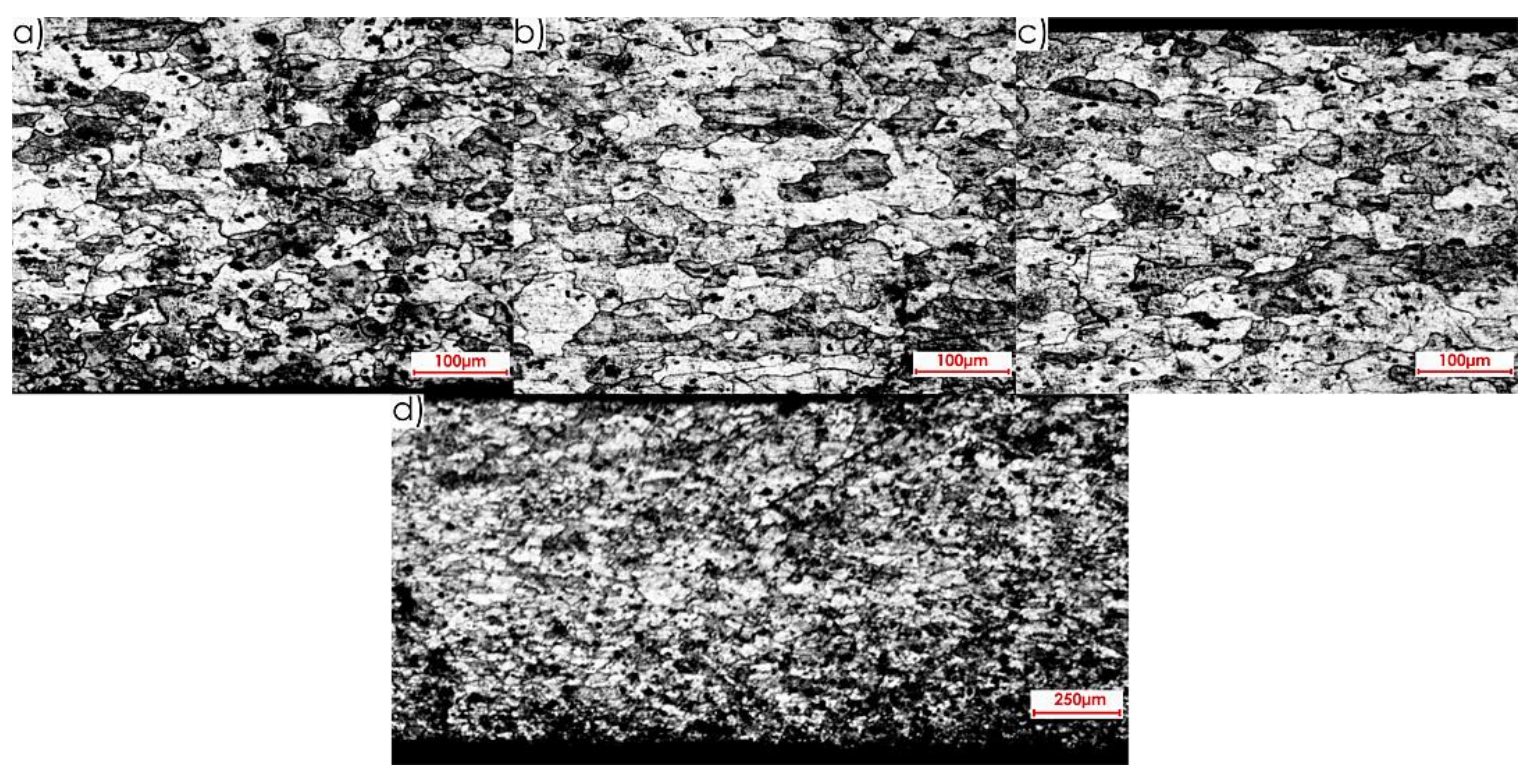

Figure 14. Microstructure after machining using the HPC technique for surface I and perpendicular rolling direction: $20 \times$ magnification: (a) surface layer after rolling, (b) core, (c) surface layer after HPC; $2.5 \times$ magnification: $(\mathbf{d})$ all sample structure view.

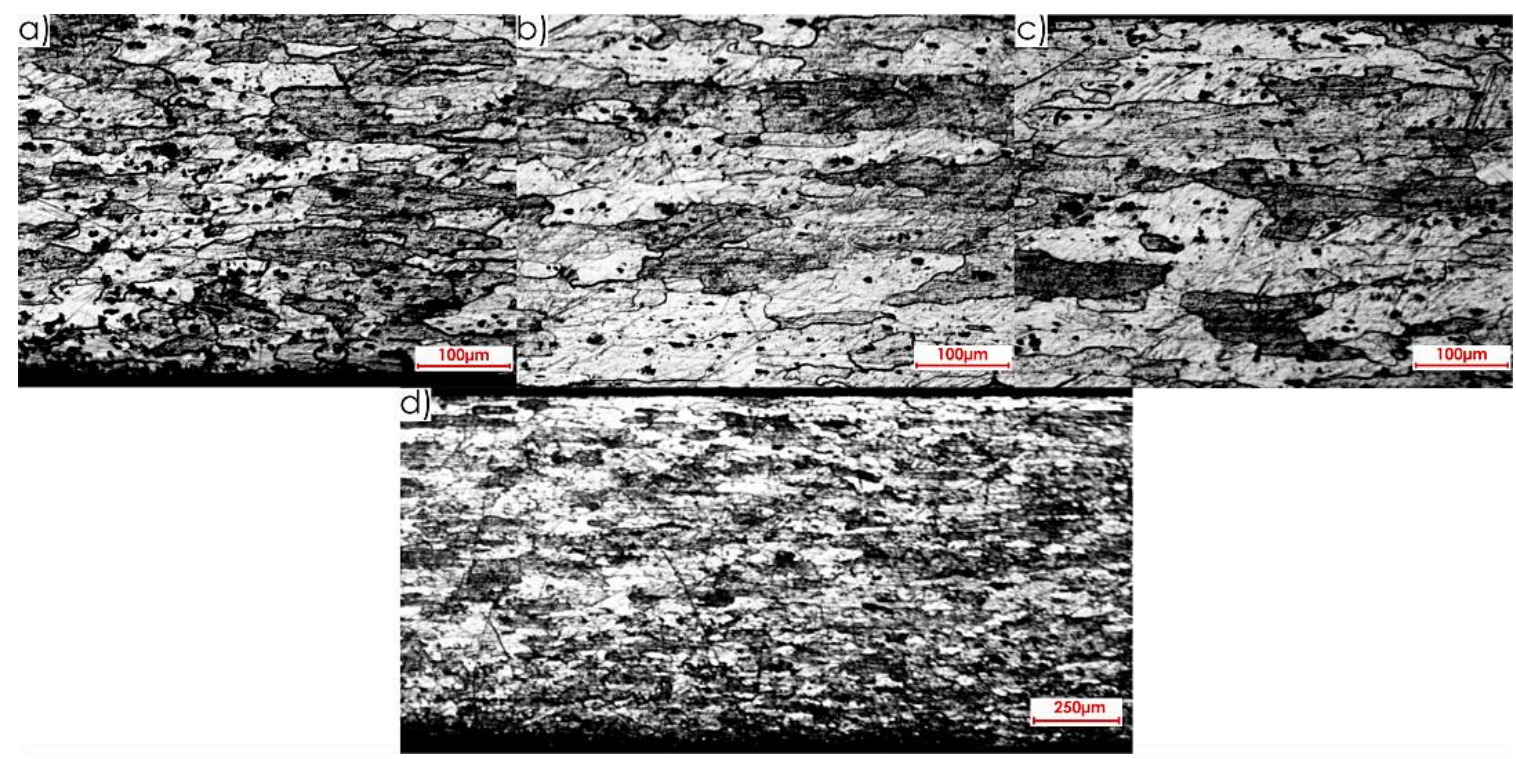

Figure 15. Microstructure after machining using the HPC technique for surface I and parallel rolling direction: 20× magnification: (a) surface layer after rolling, (b) core, (c) surface layer after HPC; $2.5 \times$ magnification: (d) all sample structure view.

On the basis of the microstructure examinations performed, a clear difference between the surface layer and the core, after both milling and rolling, was identified. Additionally, diverse structures after machining and plastic forming were observed. In the case of rolling, longer and flattened grains were obtained, and the whole textured zone had a thickness of approximately $0.4 \mathrm{~mm}$, while after milling, shorter and slightly smaller grains were received, and the textured zone was approximately $0.2 \mathrm{~mm}$. It was defined on the basis of the observation of the microstructures in an approximate way. Hence the thickness of the textured zone is $50 \%$ higher after rolling than after milling. 


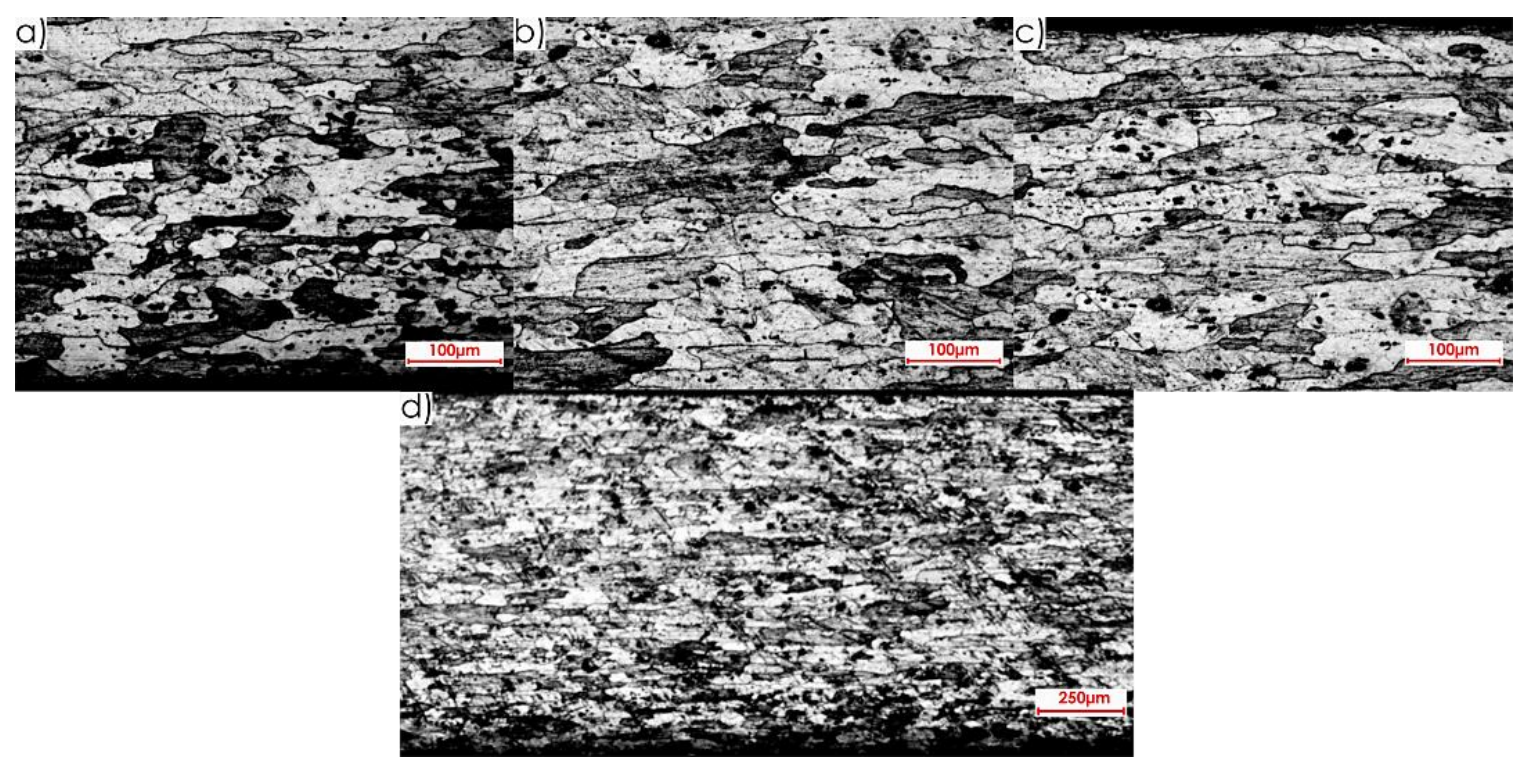

Figure 16. Microstructure after machining using the HPC technique for surface II and perpendicular rolling direction: 20× magnification: (a) surface layer after rolling, (b) core, (c) surface layer after HPC; $2.5 \times$ magnification: $(\mathbf{d})$ all sample structure view.

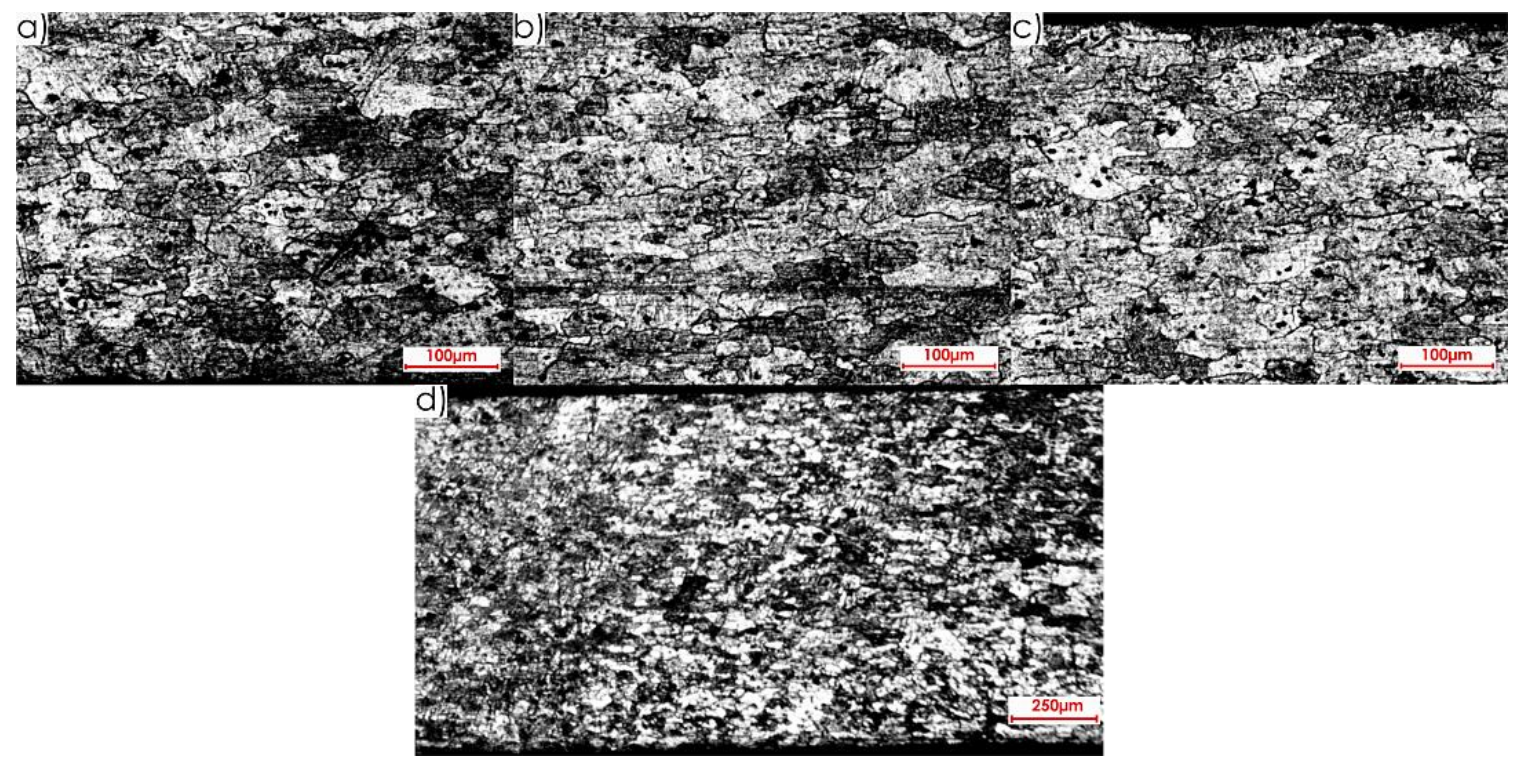

Figure 17. Microstructure after machining using the HPC technique for surface II and parallel rolling direction: 20× magnification: (a) surface layer after rolling, (b) core, (c) surface layer after HPC; $2.5 \times$ magnification: (d) all sample structure view.

In addition, it is recommended to conduct the experiment in a version with the use of a pre-machining consisting in the removal of the textured surface layer formed after rolling $(0.4 \mathrm{~mm})$, as it is highly likely that it will minimise post-machining deformations.

\section{Conclusions}

The completed research and analysis of obtained results have enabled to formulate the following conclusions:

- The removal of forces clamping a thin-walled workpiece in a clamping device creates a new dimension and shape balance under the influence of the residual stresses resulting from both rolling and milling, which results in significant deformations, invisible during the machining. 
- It is possible to minimise post-machining deformations of thin-walled elements made of EN AW-2024 T351 aluminium alloy by employing a correct milling technique.

- Larger relative deformations $\varepsilon$ were observed on longitudinal strain gauges.

- The relation between the milling direction and rolling direction exerts a significant impact on occurring deformations. Regardless of the milling technique, larger relative deformations $\varepsilon$ were obtained after milling in the direction perpendicular to the rolling direction.

- Different microstructures were observed after milling and rolling. In the case of rolling, elongated grains were obtained, and the whole textured zone had a thickness of approximately $0.4 \mathrm{~mm}$, while after machining, shorter and slightly smaller grains were obtained, and the textured zone was approximately $0.2 \mathrm{~mm}$ ( $50 \%$ less than after rolling).

Author Contributions: Conceptualization, J.K., S.L., P.P. and M.Z.-M.; methodology, P.P. and M.Z.-M.; software, P.P. and M.Z.-M.; validation, J.K., S.L., P.P. and M.Z.-M.; formal analysis, M.Z.-M.; investigation, P.P. and M.Z.-M.; resources, M.Z.-M.; data curation, P.P.; writing-original draft preparation, M.Z.-M.; writing-review and editing, J.K., and S.L.; visualization, M.Z.-M.; supervision, J.K. and S.L.; project administration, M.Z.-M.; funding acquisition, J.K. and S.L. All authors have read and agreed to the published version of the manuscript.

Funding: The project/research was financed in the framework of the project Lublin University of TechnologyRegional Excellence Initiative, funded by the Polish Ministry of Science and Higher Education (contract no. 030/RID/2018/19).

Conflicts of Interest: The authors declare no conflict of interest.

\section{References and Notes}

1. Wysmulski, P.; Dębski, H.; Różyło, P.; Falkowicz, K. A study of stability and post-critical behaviour of thin-walled composite profiles under compression. Eksploat. Niezawodn. 2016, 18, 632-637. [CrossRef]

2. Yang, Y.; Zhang, W.-H.; Ma, Y.-C.; Wan, M.; Dang, X.B. An efficient decomposition-condensation method for chatter prediction in milling large-scale thin-walled structures. Mech. Syst. Signal Pr. 2019, 121, 58-76. [CrossRef]

3. Yuan, Y.; Zhang, H.-T.; Wu, Y.; Zhu, T.; Ding, H. Bayesian Learning-Based Model-Predictive Vibration Control for Thin-Walled Workpiece Machining Processes. IEEE-ASME T. Mech. 2017, 22, 509-520. [CrossRef]

4. Kuczmaszewski, J.; Pieśko, P.; Zawada-Michałowska, M. Influence of Milling Strategies of Thin-Walled Elements on Effectiveness of their Manufacturing. Procedia Eng. 2017, 182, 381-386. [CrossRef]

5. Shamsuddin, K.A.; Ab-Kadir, A.R.; Osman, M.H. A Comparison of Milling Cutting Path Strategies for Thin-Walled Aluminium Alloys Fabrication. Int. J. Eng. Sci. 2013, 2, 1-8.

6. Matuszak, J.; Kłonica, M.; Zagórski, I. Measurements of Forces and Selected Surface Layer Properties of AW-7075 Aluminum Alloy Used in the Aviation Industry after Abrasive Machining. Materials 2019, 12, 3707. [CrossRef] [PubMed]

7. Bałon, P.; Rejman, E.; Świątoniowski, A.; Kiełbasa, B.; Smusz, R.; Szostak, J.; Cieślik, J.; Kowalski, Ł. Thin-walled Integral Constructions in Aircraft Industry. Procedia Manuf. 2020, 47, 498-504. [CrossRef]

8. Adamski, W. Practice of application and operation of the CAD/CAM systems in the worldwide aviation industry. Mechanik 2010, 11, 874-876. (In Polish)

9. Awan, W.S.; Mabrouki, T. Numerical and experimental investigations of post-machining distortions in thin machined structures considering material-induced residual stress. J. Braz. Soc. Mech. Sci. 2017, 39, 509-521. [CrossRef]

10. Kuczmaszewski, J.; Pieśko, P.; Zawada-Michałowska, M. Surface Roughness of Thin-Walled Components Made of Aluminium Alloy EN AW-2024 Following Different Milling Strategies. Adv. Sci. Technol. Res. J. 2016, 10, 150-158. [CrossRef]

11. Seguy, S.; Campa, F.J.; Lopez de Lacalle, L.N.; Arnaud, L.; Dessein, G.; Aramendi, G. Toolpath dependent stability lobes for the milling of thin-walled parts. Int. J. Mach. Mach. Mater. 2008, 4, 377-392. [CrossRef]

12. Burek, J.; Plodzień, M.; Zyłka, L.; Sułkowicz, P. High-performance end milling of aluminum alloy: Influence of different serrated cutting edge tool shapes on the cutting force. Adv. Prod. Eng. Manag. 2019, 14, 494-506. [CrossRef] 
13. Singh, A.; Agrawal, A. Comparison of deforming forces, residual stresses and geometrical accuracy of deformation machining with conventional bending and forming. J. Mater. Process. Tech. 2016, 234, 259-271. [CrossRef]

14. Borojević, S.; Lukić, D.; Milošević, M.; Vukman, J.; Kramar, D. Optimization of process parameters for machining of Al 7075 thin-walled structures. Adv. Prod. Eng. Manag. 2018, 13, 125-135. [CrossRef]

15. Kuczmaszewski, J.; Łogin, W.; Pieśko, P.; Zawada-Michałowska, M. Assessment of the Accuracy of High-Speed Machining of Thin-Walled EN AW-2024 Aluminium Alloy Elements Using Carbide Milling Cutter and with PCD Blades. In Advances in Manufacturing. Lecture Notes in Mechanical Engineering; Hamrol, A., Ciszak, O., Legutko, S., Jurczyk, M., Eds.; Springer: Cham, Germany, 2018; pp. 671-680. [CrossRef]

16. Kuczmaszewski, J.; Pieśko, P.; Zawada-Michałowska, M. Analysis of cutting speed influence on the deformation of thin-walled elements made of aluminium alloy EN AW-2024 after milling. Mechanik 2016, 8-9, 1066-1067. (In Polish) [CrossRef]

17. Ratchev, S.; Liu, S.; Becker, A.A. Error compensation strategy in milling flexible thin-wall parts. J. Mater. Process. Tech. 2005, 162-163, 673-681. [CrossRef]

18. Zębala, W. Errors minimalisation of thin-walled parts machining. Inżynieria Masz. 2010, 3, 45-54. (In Polish)

19. Gao, H.; Zhang, Y.; Wu, Q.; Song, J. An analytical model for predicting the machining deformation of a plate blank considers biaxial initial residual stresses. Int. J. Adv. Manuf. Tech. 2017, 93, 1473-1486. [CrossRef]

20. Kłonica, M.; Kuczmaszewski, J.; Matuszak, J.; Pałka, T.; Pieśko, P.; Rusinek, R.; Włodarczyk, M.; Zagórski, I.; Zaleski, K. Machining of Aluminum and Magnesium Alloys; Kuczmaszewski, J., Zaleski, K., Eds.; Politechnika Lubelska: Lublin, Poland, 2015. (In Polish)

21. Lu, L.X.; Sun, J.; Li, Y.L.; Li, J.F. A Theoretical Model for Load Prediction in Rolling Correction Process of Thin-Walled Aeronautic Parts. Int. J. Adv. Manuf. Tech. 2017, 92, 4121-4131. [CrossRef]

22. Fu, W.-E.; Cohen, P.H.; Ruud, C.O. Experimental investigation of the machining induced residual stress tensor under mechanical loading. J. Manuf. Process. 2009, 11, 88-96. [CrossRef]

23. Senczyk, D. Residual Stresses_Introduction to Generation, Control and Use; Wydawnictwo Politechniki Poznańskiej: Poznań, Poland, 1996. (In Polish)

24. Singh, A.; Agrawal, A. Investigation of surface residual stress distribution in deformation machining process for aluminum alloy. J. Mater. Process. Tech. 2015, 225, 195-202. [CrossRef]

25. Kuczmaszewski, J.; Łogin, W.; Pieśko, P.; Zagórski, I. State of Residual Stresses after the Process of Milling Selected Aluminium Alloys. Adv. Sci. Technol. Res. J. 2018, 12, 63-73. [CrossRef]

26. Olszak, W. Machining; Wydawnictwa Naukowo-Techniczne: Warszawa, Poland, 2009. (In Polish)

27. Krajewska-Śpiewak, J.; Gawlik, J.; Piekoszewski, W.; Stachura, K. Identification of Residual Stresses in a Surface Layer of Ti6AL4V and Inconel 718 after Process of Peripheral Milling. Teh Vjesn 2018, 25, 88-91. [CrossRef]

28. Li, B.; Jiang, X.; Yang, J.; Liang, S.Y. Effects of depth of cut on the redistribution of residual stress and distortion during the milling of thin-walled part. J. Mater. Process. Tech. 2015, 216, 223-233. [CrossRef]

29. Rafey Khan, A.; Nisar, S.; Shah, A.; Khan, M.A.; Khan, S.Z.; Sheikh, M.A. Reducing machining distortion in AA 6061 alloy through re-heating technique. Mater. Sci. Tech. Lond. 2017, 33, 731-737. [CrossRef]

30. Shet, C.; Deng, X. Residual stresses and strains in orthogonal metal cutting. Int. J. Mach. Tools Manuf. 2003, 43, 573-587. [CrossRef]

31. Tang, Z.T.; Liu, Z.Q.; Pan, Y.Z.; Wan, Y.; Ai, X. The influence of tool flank wear on residual stresses induced by milling aluminum alloy. J. Mater. Process. Techn. 2009, 209, 4502-4508. [CrossRef]

32. Cerutti, X.; Mocellin, K.; Hassini, S.; Blaysat, B.; Duc, E. Methodology for aluminium part machining quality improvement considering mechanical properties and process conditions. Cirp J. Manuf. Sci. Tech. 2017, 18, 18-38. [CrossRef]

33. Jiang, X.; Wang, Y.; Ding, Z.; Li, H. An approach to predict the distortion of thin-walled parts affected by residual stress during the milling process. Int. J. Adv. Manuf. Tech. 2017, 93, 4203-4216. [CrossRef]

34. Kuczmaszewski, J.; Pieśko, P.; Zawada-Michałowska, M. Evaluation of the impact of the natural seasoning process on post-machining deformation of thin-walled elements made of aluminium alloy EN AW-2024. IOP Conf. Ser. Mater. Sci. Eng. 2018, 393, 1-7. [CrossRef]

35. Li, P.; Liu, Y.; Gong, Y.; Li, L.; Liu, K.; Sun, Y. New deformation prediction of micro thin-walled structures by iterative FEM. Int. J. Adv. Manuf. Tech. 2018, 95, 2027-2040. [CrossRef] 
36. Zawada-Michałowska, M.; Kuczmaszewski, J.; Pieśko, P. Influence of pre-machining on post-machining deformation of thin-walled elements made of aluminium alloy EN AW-2024. IOP Conf. Ser. Mater. Sci. Eng. 2018, 393, 1-8. [CrossRef]

37. Aijun, T.; Zhanqiang, L. Deformations of thin-walled plate due to static end milling force. J. Mater. Process. Tech. 2008, 206, 345-351. [CrossRef]

38. Ma, Y.; Liu, S.; Feng, P.F.; Yu, D.W. Finite element analysis of residual stresses and thin plate distortion after face milling. In Proceedings of the 12th International Bhurban Conference on Applied Sciences and Technology (IBCAST), Islamabad, Pakistan, 13-17 January 2015; pp. 67-71. [CrossRef]

39. Zagórski, I.; Kulisz, M.; Kłonica, M.; Matuszak, J. Trochoidal Milling and Neural Networks Simulation of Magnesium Alloys. Materials 2019, 12, 2070. [CrossRef] [PubMed]

40. Zhang, C.; Jiao, S.; Wang, L. Clamping deformation analysis and machining parameter optimization of weak stiffness ring parts. IOP Conf. Ser. Mater. Sci. Eng. 2019, 493, 1-7. [CrossRef]

41. Zhang, C.; Wang, L.; Zu, X.; Meng, W. Multi-objective optimization of experimental and analytical residual stresses in pre-stressed cutting of thin-walled ring using glowworm swarm optimization algorithm. Int. J. Adv. Manuf. Tech. 2020, 107, 3897-3908. [CrossRef]

42. Arnaud, L.; Gonzalo, O.; Seguy, S.; Jauregi, H.; Peigné, G. Simulation of low rigidity part machining applied to thin-walled structures. Int. J. Adv. Manuf. Tech. 2011, 54, 479-488. [CrossRef]

43. Izamshah, R. Hybrid Deflection Prediction for Machining Thin-Wall Titanium Alloy Aerospace Component. Ph.D. Thesis, School of Aerospace, Mechanical and Manufacturing Engineering RMIT University, Melbourne, Australia, 2011.

44. Pieśko, P. Research on the Influence of Static Stiffness of Shank Cutters on the Geometrical Accuracy of Workpieces Made of Aluminum Alloy. Ph.D. Thesis, Lublin University of Technology, Lublin, Poland, 2015. (In Polish).

45. Królczyk, G.; Legutko, S.; Nieslony, P.; Gajek, M. Study of the surface integrity microhardness of austenitic stainless steel after turning. Teh. Vjesn. 2014, 21, 1307-1311.

46. Maruda, R.; Feldshtein, E.; Legutko, S.; Królczyk, G. Research on Emulsion Mist Generation in the Conditions of Minimum Quantity Cooling Lubrication (MQCL). Teh. Vjesn. 2015, 22, 1213-1218. [CrossRef]

47. Sandvik, Machining Tutorial. Available online: https://www.sandvik.coromant.com/en-gb/pages/default. aspx (accessed on 25 July 2020).

48. Bałon, P.; Rejman, E.; Smusz, R.; Szostak, J.; Kiełbasa, B. Implementation of high speed machining in thin-walled aircraft integral elements. Open Eng. 2018, 8, 162-169. [CrossRef]

49. Bałon, P.; Rejman, E.; Smusz, R.; Kiełbasa, B. High speed machining of the thin-walled aircraft constructions. Mechanik 2017, 8-9, 726-729. (In Polish)

50. Adamski, W. Impact of Modern Manufacturing Technologies at Aircraft Design. Mechanik 2015, 12, 1-5. (In Polish) [CrossRef]

51. Wang, J.; Ibaraki, S.; Matsubara, A. A cutting sequence optimization algorithm to reduce the workpiece deformation in thin-wall machining. Precis. Eng. 2017, 50, 506-514. [CrossRef]

52. Smith, S.; Wilhelm, R.; Dutterer, B.; Cherukuri, H.; Goel, G. Sacrificial structure preforms for thin part machining. CIRP Ann. Manuf. Techn. 2012, 61, 379-382. [CrossRef]

53. European Standards. Aluminium and Aluminium Alloys-Chemical Composition and Form of Wrought ProductsPart 1: Numerical Designation System; PN-EN 573-1:2006.

54. European Standards. Aluminium and Aluminium Alloys-Sheet, Tape, Plate-Part 2: Mechanical Properties; PN-EN 485-2+A1:2018-12.

55. Kennametal, tool catalogue, Kennametal, Pittsburgh, Pennsylvania, USA.

56. Sandvik, tool catalogue, Sandvik, Stockholm, Sweden.

Publisher's Note: MDPI stays neutral with regard to jurisdictional claims in published maps and institutional affiliations. 